\title{
Time Course of Early Metabolic Changes following Diffuse Traumatic Brain Injury in Rats as Detected by ${ }^{1} \mathrm{H}$ NMR Spectroscopy
}

\author{
JOSÉ M. PASCUAL, ${ }^{1}$ JUAN SOLIVERA, ${ }^{2}$ RUTH PRIETO, ${ }^{3}$ LAURA BARRIOS, ${ }^{4}$ \\ PILAR LÓPEZ-LARRUBIA, ${ }^{5}$ SEBASTIAN CERDÁN, ${ }^{5}$ and JOSÉ M. RODA ${ }^{3}$
}

\begin{abstract}
Experimental models of traumatic brain injury (TBI) provide a useful tool for understanding the cerebral metabolic changes induced by this pathological condition. Here, we report on the time course of changes in cerebral metabolites after TBI and its correlation with early brain morphological changes using a combination of high-resolution proton magnetic resonance spectroscopy $\left({ }^{1} \mathbf{H}\right.$ MRS) and magnetic resonance imaging (MRI). Adult male Sprague-Dawley rats were subjected to closed head impact and examined by MRI at 1, 9, 24, 48, and and $72 \mathrm{~h}$ after the injury. Extracts from funnel frozen rat brains were then obtained and analyzed quantitatively by high-resolution ${ }^{1}$ H MRS. Finally, statistical multivariate analysis was carried out to identify the combination of cerebral metabolites that best described the time evolution of diffuse TBI. The temporal changes observed in the concentration of cerebral metabolites followed three different patterns. The first pattern included taurine, threonine, and glycine, with concentrations peaking $24 \mathrm{~h}$ after the injury. The second pattern included glutamate, GABA, and alanine, with concentrations remaining elevated between 24 and $48 \mathrm{~h}$ post-injury. The third one involved creatine-phosphocreatine, $N$-acetylaspartate, and myo-inositol, with concentrations peaking $48 \mathrm{~h}$ after the injury. A multivariate stepwise discriminant analysis revealed that the combination of the organic osmolytes taurine and myo-inositol allowed optimal discrimination among the different time groups. Our findings suggest that the profile of some specific brain molecules that play a role as organic osmolytes can be used to follow-up the progression of the early diffuse brain edema response induced by TBI.
\end{abstract}

Key words: brain edema; ${ }^{1} \mathrm{H}-\mathrm{NMR}$ spectroscopy; myo-inositol; organic osmolyte; taurine; traumatic brain injury

\footnotetext{
${ }^{1}$ Department of Neurosurgery, La Princesa University Hospital, Madrid, Spain.

${ }^{2}$ Department of Neurosurgery, Sant Creu and Sant Pau University Hospital, Barcelona, Spain.

${ }^{3}$ Department of Neurosurgery, La Paz University Hospital, Madrid, Spain.

${ }^{4}$ Statistics Department, Computing Technical Center, C.S.I.C., Madrid, Spain.

${ }^{5}$ Biomedical Research Institute “Alberto Sols," C.S.I.C., Madrid, Spain.
} 


\section{INTRODUCTION}

$\mathbf{T}$ HE DEVELOPMENT OF EXPERIMENTAL MODELS of traumatic brain injury (TBI) has proved to be a useful tool for the investigation of the pathophysiological mechanisms underlying the different types of post-traumatic brain damage (Morales et al., 2005). Among the wide range of post-traumatic brain lesions observed in clinical settings, the early response of diffuse brain swelling represents one of the major factors influencing the outcome of patients who have suffered TBI (Kimelberg, 1995; Unterberg et al., 2004). Nevertheless, the actual pathophysiological events involved in this response remain unclear (Klatzo, 1967; Lobato, 1993; Marmarou, 2003). Some authors consider that a net brain water increase is the main cause of the post-traumatic brain swelling (Marmarou, 1994; Ito et al., 1996; Marmarou et al., 2000), whereas others have obtained evidence of a vascular engorgement as an important contributor (Obrist et al., 1994; Kelly et al., 1996; Bouma et al., 1998). The closed head injury model induced by impact acceleration, as designed by Marmarou et al. (2000), has appropriately reproduced the diffuse brain swelling observed in human patients after a severe head injury (Foda et al., 1994; Marmarou et al., 1994). This model has demonstrated a relatively short breakdown of the blood-brain barrier, followed by a long-lasting intracellular glial edema, as the main cause of the diffuse post-traumatic brain swelling, with no apparent contribution of vascular engorgement.

After a severe closed head injury, the diffuse brain swelling experienced by some patients usually shows a prolonged evolution, with the maximum edema and highest level of intracranial pressure occurring 3-5 days after the injury (Marshall et al., 1991; Lobato, 1993). However, little is known about the ongoing relationships between the progression of post-traumatic brain swelling and the associated sequential metabolic changes occurring in the damaged brain. Some intracellular molecules with osmotic properties, termed "organic osmolytes," have been shown to play an important role in the maintenance of long-lasting volume changes of brain cells under pathological conditions (McManus et al., 1995; Lang et al., 1998; Pasantes-Morales et al., 2000). In particular, an increment in the brain content of some of these organic osmolytes has been observed by proton magnetic resonance spectroscopy $\left({ }^{1} \mathrm{H}\right.$ MRS) in patients suffering from chronic hypernatremia (Lee et al., 1994). ${ }^{1} \mathrm{H}$ MRS has developed in recent years into a useful tool for measuring changes in several cerebral metabolites; however, the limited resolution and sensitivity of in vivo ${ }^{1} \mathrm{H} \mathrm{MRS}$ results in the detection of only a few molecules (Lin et al., 2005). The analysis ex vivo of whole brain extracts by high-resolution ${ }^{1} \mathrm{H}$ MRS is ideally suited to investi- gate the evolution of the cerebral metabolic profile after TBI, because of its ability to detect resonances from a larger number of brain metabolites (Cerdan et al., 1985, 1990). The metabolic effects of TBI are known to be quite complex, affecting, to different degrees, a plethora of cerebral compounds. It thus becomes necessary to implement techniques that identify the most relevant changes, describing unambiguously the cerebral metabolic status at different times post-injury. The statistical methods of multivariate stepwise discriminant analysis can fulfill this role, identifying the most relevant patterns of metabolites that best describe a given pathophysiological situation.

This study analyzes the early changes in the concentration of cerebral metabolites during the progression of diffuse post-traumatic brain damage. We obtained ${ }^{1} \mathrm{H} \mathrm{MR}$ spectra from rat brain extracts at increasing times after a closed head injury, and then used a statistical method of stepwise multivariate discriminant analysis in order to identify the metabolic profile that best characterized each time interval after the traumatic event. With this aim, this work implemented and validated a protocol of high-resolution ${ }^{1} \mathrm{H}$ MRS and multivariate analysis to identify the most distinctive early changes shown by some specific cerebral metabolites, with a known role as organic osmolytes, in an experimental model of TBI in which a response of diffuse brain swelling predominates. Our findings revealed that the progression of the diffuse traumatic brain swelling response elicited by Marmarou's closed head injury model involved early and significant changes in the concentration of some cerebral organic osmolytes that allowed prediction of the evolution of the lesion.

\section{METHODS}

\section{Traumatic Brain Injury Model}

The experimental protocols used in this study were approved by appropriate institutional committees on animal welfare and meet the guidelines of the European Communities Council Directive 86/609/EEC. Adult male Sprague-Dawley rats (280-310 g) received water and food ad libitum before the experiments. The animals received no ventilator support at any time during the procedure. Anesthesia was induced with $4 \%$ isoflurane and maintained with $1 \%$ isoflurane using a face mask.

Marmarou's model of diffuse brain injury was used to induce TBI (Foda et al., 1994; Marmarou et al., 1994). Briefly, after being anesthetized, each animal calvaria was exposed by a midline incision, and a stainless steel disc was fixed on the skull between the coronal and lambdoid sutures. A 450-g brass weight was freely dropped onto the steel through a Plexiglas tube from a height of $2 \mathrm{~m}$. Thirty-seven rats were subjected to head impact, and 
four others were sham operated. Typically, animals suffering closed head injury showed a variable period of convulsions and apnea following the impact. Those rats that did not spontaneously recover from trauma were not resuscitated and were excluded from the analysis.

Five different groups, each one consisting of four animals, were used. The first group (group 1) consisted solely of the sham-operated rats. The remaining four groups underwent closed head injury and were sacrificed at $9 \mathrm{~h}$ (group 2), $24 \mathrm{~h}$ (group 3), $48 \mathrm{~h}$ (group 4), and 72 h (group 5) after the injury, respectively. One animal per group was investigated by magnetic resonance imaging (MRI) prior to processing for high-resolution ${ }^{1} \mathrm{H}$ MRS. In addition, an MRI study was carried out pre-injury and at $1,9,24,48$, and $72 \mathrm{~h}$ post-injury in a separate group of five animals, in order to assess the time course of morphological alterations as observed on $\mathrm{T}_{2}$-weighted $\mathrm{MR}$ images.

\section{Brain Water Content Measurement}

A separate set of animals was used to investigate the time course of cerebral water content. Closed head injury was induced in these rats as indicated previously, and the brains of the surviving animals were extracted from funnel frozen heads at 1, 9, 24, 48, and $72 \mathrm{~h}$ after injury. Five animals per time group were finally included in this analysis, and an additional group of five sham operated rats was used as control. The five animals corresponding to the 72-h group were used for the MRI assessment of morphological changes during the first $72 \mathrm{~h}$ before being sacrificed for the analysis of brain water content. Preweighted frozen cerebral specimens, excluding the cerebellum and brain stem, were desiccated for $96 \mathrm{~h}$ at $150^{\circ} \mathrm{C}$, until the weight of the dry tissue was constant. The brain water content was calculated as the difference between wet and dry weights, and then converted to a percentage. The percentage of brain water in the tissue is calculated (Alexander 2005) as:

(wet weight - dry weight) $\times 100 /$ wet weight

\section{Magnetic Resonance Imaging}

All MRI studies were performed on a 7-Tesla MR Bruker Pharmascan (Biospin, Ettlingen, Germany) using a 38-mm ${ }^{1} \mathrm{H}$ selective resonator and a Multislice Multiecho sequence. Animals subjected to this procedure (six rats per time group) were re-anesthetized with isoflurane as previously indicated. Acquisition conditions of $\mathrm{T}_{2^{-}}$ weighted images were as follows: TR, $2500 \mathrm{msec}$, TE, $60 \mathrm{msec}$, FOV, $30 \mathrm{~mm}$; matrix size, $256 \times 192$; number of averages, 3; data matrix, $256 \times 192$; slice thickness, $1.5 \mathrm{~mm}$; interslice distance, $1.6 \mathrm{~mm}$.

\section{Preparation of Brain Extracts}

Once the desired interval of time post-injury was reached, the animals were re-anesthetized with isoflurane and their brains funnel frozen with liquid nitrogen (Lust et al., 1989). The entire frozen brains were removed from the skull, and after removing the cerebellum and adjacent lower medulla with a chisel, they were pulverized in liquid nitrogen. Acid-soluble metabolite extracts from individual brains were prepared, neutralized, and freeze dried until performing ${ }^{1} \mathrm{H}$ MRS analysis, as described previously (Pascual et al., 1998). Lyophilized extracts were resuspended in $\mathrm{D}_{2} \mathrm{O}(99.9 \% \mathrm{D})$, and the $\mathrm{pH}$ was adjusted to 7.3 just prior to high-resolution ${ }^{1} \mathrm{H}$ MRS analysis.

\section{${ }^{1}$ H Magnetic Resonance Spectroscopy}

High-resolution ${ }^{1} \mathrm{H}$ MRS $\left(360.13 \mathrm{MHz}, \mathrm{pH} 7.3,22^{\circ} \mathrm{C}\right)$ analysis of brain extracts was performed at 8.4 Tesla in a Bruker AM-360 spectrometer using a commercial 5$\mathrm{mm}{ }^{1} \mathrm{H}$ selective probe. Acquisition conditions were $90^{\circ}$ pulses, 16.9-sec total cycle time, and 16,384 data points acquired in the time domain with an acquisition time of $1.901 \mathrm{sec}$. The intensity of the residual water signal was reduced with a 5-sec presaturating pulse centered on the water frequency. Sixty-four scans were sufficient to obtain an optimum signal-to-noise ratio. Prior to Fourier transformation, free induction decays were multiplied by an exponential function, resulting in $0.25-\mathrm{Hz}$ artificial line broadening in the transformed spectrum. Further spectral processing, including phase and baseline corrections and peak areas integrals, was carried out by the same operator, using Bruker 1D WIN NMR software. Chemical shifts were referred to the methyl signal of $2,2^{\prime}-3,3^{\prime}-$ tetradeutero-trimethyl-silyl-propionate (TSP; $1 \mathrm{mM}$ ) at 0 ppm. Metabolite assignments were performed using literature values and confirmed, when necessary, with the addition of the authentic compounds (Behar et al., 1981; Cerdan et al., 1985). Peak integrals were determined by standard non-linear curve-fitting using the complex Lorentzian lineshape function and normalized to the area of the TSP reference. The concentration of the different metabolites was calculated as described earlier (Cerdan et al., 1985), by determining the ratio of the resonance area of a specific proton from the metabolite to the known concentration of TSP, and correcting it for the different numbers of protons originating each resonance:

$$
\text { [Metabolite } Y]=\text { area of } Y \times 9 / \text { area TSP } \times n
$$

where 9 and $n$ refer, respectively, to the number of protons from the trimethyl group of TSP and the number of protons originating the considered resonance from the metabolite. 
The following specific resonances were used in the quantitation: threonine H3 (1.25 ppm), lactate H3 (1.35 ppm), alanine H3 (1.48 ppm), acetate H2 (1.93 ppm), NAA methyl (2.05 ppm), GABA H2 (2.28 ppm), glutamate H4 (2.35 ppm), glutamine H4 (2.45 ppm), aspartate $\mathrm{H} 2$ (2.82 ppm), Cr/PCr (3.05 ppm), choline-containing compounds methyl (3.20 ppm), taurine H1 (3.43 ppm), glycine H2 (3.56 ppm), and Ino H4,H6 (3.62 ppm).

\section{Statistical Analysis}

Statistical analysis was performed using the SPSS Package (v.13, SPSS Inc., Chicago, IL) as implemented on a Windows XP platform. The experimental data set consisted of 20 rat brain samples, derived from the five different time groups. A total of 15 metabolites were considered in the analysis of each sample. First, a univariate analysis of variance (ANOVA) test was run to demonstrate the time dependence of the global metabolite changes observed. Then, the statistical significance of the changes occurring for each metabolite between consecutive times intervals was investigated using the Bonferroni and Dunnett multiple comparisons tests (Weber et al., 2000). Finally, a multivariate stepwise linear discriminant analysis was carried out to search for the optimal combination of metabolites that could best describe and discriminate among the different time groups. Briefly, for a classification of a cerebral extract between two different time groups, $i$ and $j$ after TBI, the classification functions $f_{i}$ and $f_{j}$ (Eqs. 1 and 2) contain the linear combination of metabolites $x_{t}$ that best discriminate between the times compared (Afifi et al., 2004).

$$
\begin{aligned}
& f_{i}=\sum_{t=1}^{k} a_{i t} x_{t}+a_{0} \\
& f_{j}=\sum_{t=1}^{k} b_{j t} x_{t}+b_{0}
\end{aligned}
$$

The classification functions contain independent terms $a_{0}$ and $b_{0}$, and each metabolite is multiplied by a coefficient $a_{i t}$ or $b_{j t}$ that reveals its statistical weight. No more than two metabolites were used in every classification $(k=2)$. The Fisher discriminant function $F_{i j}$ describing this comparison is calculated as indicated in Eqs. 3, 4, and 5:

$$
\begin{gathered}
Z=\sum_{t=1}^{k} a_{i t} x_{t}-\sum_{t=1}^{k} b_{j t} x_{t} \\
C=a_{0}-b_{0} \\
F_{i j}=Z+C
\end{gathered}
$$

For a binary comparison of a cerebral extract between post-traumatic time groups $i$ and $j$, a positive value of the
Fisher function $F_{i j}$ classifies the extract in time $i$, and a negative value classifies the extract in time $j$. The probabilities that the investigated extract belongs to time groups $i$ or $j\left(p_{i}\right.$ or $p_{j}$, respectively) are given by the following expressions, respectively: $p_{i}=1 /\left[1+\exp \left(-F_{i j}\right)\right]$ or $p_{j}=1-p_{i}$.

\section{RESULTS}

\section{Survival Rates and Physiological Parameters}

Table 1 summarizes some relevant physiopathological variables during TBI, including the time until death after the impact and the mortality rates of the different time groups. A total of 37 animals were subjected to the closed head injury protocol in order to obtain four surviving subjects for ${ }^{1} \mathrm{H}$ MRS study in each group, resulting in a global mortality value of $56.8 \%$ after head impact. This figure agrees well with the mortality observed in the original experimental model, as implemented with the fall of a brass of $450 \mathrm{~g}$ from $2 \mathrm{~m}$ in height (Marmarou et al., 2004). Table 1 also presents the body weight, convulsions after head impact, apnea periods and their length, mortality rate and time elapsed until death in these animals. None of the rats that survived beyond the first 90 min died during the experimental protocol. Thirty-two animals out of 37 suffered severe generalized convulsions lasting, on average, $24 \pm 13 \mathrm{sec}$. None of the surviving animals sustained depressed skull fractures.

\section{Cerebral Water Content Analysis}

Brain water content values calculated by the dryweight method in each group at sequential time points post-injury (expressed as mean percentage \pm SD) were: $81.64 \pm 0.47 \%$ (sham), $81.19 \pm 6.88 \%(1 \mathrm{~h})$, $80.93 \pm 0.9 \%(9 \mathrm{~h}), 81.59 \pm 0.15 \%(24 \mathrm{~h}), 81.31 \pm$ $1.02 \%(48 \mathrm{~h})$, and $81.33 \pm 0.34 \%(72 \mathrm{~h})$. The water content did not changed significantly in the injured brain among the different time groups. These findings reveal this method as unable to detect significant increments of water content in the post-injured whole brain as compared with controls, in contrast with the small but significant $1-2 \%$ net water gain observed on this model $24 \mathrm{~h}$ post-injury by T1-weighted MRI maps, probably a more sensitive method (Barzó et al., 1997). Since this TBI model induces a predominant intracellular swelling, our findings support the idea of a water shift from the extracellular into the intracellular compartment as the main cause of post-traumatic diffuse brain swelling. 
PASCUAL ET AL.

Table 1. Body Weight, Convulsion Period (sec), Apnea, Time to Death, and Mortality Rates in Each Time Group after Traumatic Brain Injury

\begin{tabular}{|c|c|c|c|c|c|c|}
\hline & $\begin{array}{l}\text { No. of } \\
\text { rats }\end{array}$ & $\begin{array}{l}\text { Weight } \\
(g)\end{array}$ & $\begin{array}{c}\text { Convulsions } \\
(s)\end{array}$ & $\begin{array}{l}\text { Apnea } \\
(s)\end{array}$ & $\begin{array}{l}\text { Time to death } \\
\text { (min) }\end{array}$ & Mortality rate $\mathrm{a}^{\mathrm{a}}$ \\
\hline Sham $^{b}$ & 4 & $284 \pm 5^{\mathrm{c}}$ & - & - & - & - \\
\hline $9 \mathrm{~h}$ & 8 & $314 \pm 12$ & $14 \pm 12^{\mathrm{c}}(7)^{\mathrm{d}}$ & $15 \pm 10^{c}$ & - & $50.0 \%$ \\
\hline Survivors & 4 & $319 \pm 10$ & $17 \pm 13(3)$ & $11 \pm 6$ & - & \\
\hline Died after recovery & 1 & 302 & $15(1)$ & 30 & 10 & \\
\hline Did not recover & 3 & $311 \pm 14$ & $11 \pm 16$ & - & - & \\
\hline $24 \mathrm{~h}$ & 13 & $294 \pm 12$ & $33 \pm 9(12)$ & $31 \pm 15$ & - & $69.2 \%$ \\
\hline Survivors & 4 & $305 \pm 14$ & $27 \pm 8(3)$ & $26 \pm 18$ & - & \\
\hline Died after recovery & 3 & $295 \pm 9$ & $39 \pm 5(3)$ & $38 \pm 3$ & $36 \pm 23$ & \\
\hline Did not recover & 6 & $286 \pm 4$ & $33 \pm 9(6)$ & - & - & \\
\hline $48 \mathrm{~h}$ & 5 & $314 \pm 16$ & $14 \pm 5(4)$ & $14 \pm 14$ & - & $20.0 \%$ \\
\hline Survivors & 4 & $321 \pm 5$ & $12 \pm 3(3)$ & $14 \pm 14$ & - & \\
\hline Died after recovery & - & - & - & - & - & \\
\hline Did not recover & 1 & 287 & $20(1)$ & - & - & \\
\hline $72 \mathrm{~h}$ & 11 & $293 \pm 12$ & $26 \pm 14(9)$ & $40 \pm 24$ & - & $63.6 \%$ \\
\hline Survivors & 4 & $301 \pm 17$ & $32 \pm 3(3)$ & $30 \pm 26$ & - & \\
\hline Died after recovery & 3 & $291 \pm 8$ & $29 \pm 16(3)$ & $54 \pm 14$ & $42 \pm 16$ & \\
\hline Did not recover & 4 & $288 \pm 8$ & $16 \pm 17$ & - & - & \\
\hline
\end{tabular}

aTotal mortality rate in all the trauma groups was $56.8 \%$.

${ }^{\mathrm{b}}$ Results are given as mean \pm standard deviation.

'Sham was surgery without trauma; the rest of the groups are expressed as sacrifice time after the trauma.

${ }^{\mathrm{d}}$ The number of animals presenting convulsions $(n)$ is given in parentheses.

\section{Post-Traumatic Brain Alterations as Detected by Magnetic Resonance Imaging}

Figure 1 illustrates the evolution of morphological changes induced by TBI, as observed on $\mathrm{T}_{2}$-weighted MRI in two coronal sections taken at the level of the hippocampus (bottom) and the midbrain (top). Two main MRI signal changes were consistently observed on the first hour postinjury in all the six animals investigated: (i) the disappearance of the bright signal area corresponding to the cerebrospinal fluid cistern around the midbrain (top arrows) and (ii) the appearance of hyperintense areas confined in both hyppocampi (bottom arrows). These tissue alterations are probably related to the early development of post-traumatic brain swelling and both signs tended to resume progressively. The hyperintense signal corresponding to the cerebrospinal fluid cistern recovered after $24 \mathrm{~h}$, while the hippocampal hyperintensities faded gradually for the next $72 \mathrm{~h}$ after the injury, following a dorso-ventral direction (see arrowheads in the 72-h bottom panel). No additional signal changes were apparent in the cortical areas or basal ganglia on T2-weighted MR images.

\section{Post-Traumatic Cerebral Metabolic Changes as Detected by ${ }^{1} H$ NMR Spectroscopy}

Figure 2 depicts a representative high-resolution ${ }^{1} \mathrm{H}$ NMR spectrum of a rat brain $48 \mathrm{~h}$ after TBI. The spec- trum shows resonances from 15 different metabolites, including mainly lactate $\mathrm{H} 3\left(-\mathrm{CH}_{3}\right)$, alanine $\mathrm{H} 3\left(-\mathrm{CH}_{3}\right)$, acetate $\mathrm{H} 2 \quad\left(-\mathrm{CH}_{3}\right), N$-acetylaspartic $\mathrm{H} 6\left(-\mathrm{NH}-\mathrm{CH}_{3}\right)$, glutamate and glutamine $\mathrm{H} 4$ and $\mathrm{H} 3\left(-\mathrm{CH}_{2}-\right)$, creatine/phosphocreatine $\left(-\mathrm{CH}_{3}\right)$, choline derivatives $\left(-\mathrm{N}\left(\mathrm{CH}_{3}\right)_{3}\right)$, taurine (-CH- $\mathrm{NH}_{2}$ and $\left.-\mathrm{CH}-\mathrm{SO}_{3} \mathrm{H}\right)$, and myoinositol $\mathrm{H} 4, \mathrm{H} 6(-\mathrm{CHOH})$.

Table 2 summarizes the quantitative analysis of ${ }^{1} \mathrm{H}$ MRS observable metabolite content in brain extracts obtained from animals at increasing times after TBI. Since no significant differences in cerebral water content was observed between the control sham-operated group and each evolution time-point group after injury, the absolute concentration values for every cerebral metabolites were determined as $\mu \mathrm{mol}$ per gram of wet tissue.

The time course of changes observed in the different metabolites can be described by three different patterns (Fig. 3, top pannels). Taurine (Tau), threonine, and glycine depict Pattern 1, characterized by a maximum concentration reached at $24 \mathrm{~h}$ after TBI. Pattern 2 includes glutamate (Glu), GABA, and alanine, and is characterized by the maximum concentration being maintained between 24 and 48 h. Finally, creatine, phosphocreatine $(\mathrm{Cr} / \mathrm{PCr}), N$-acetylaspartate (NAA), and myoinositol (Ino) exhibit Pattern 3, as characterized by a maximum concentration of the molecule being reached at 48 $h$ after the injury. 

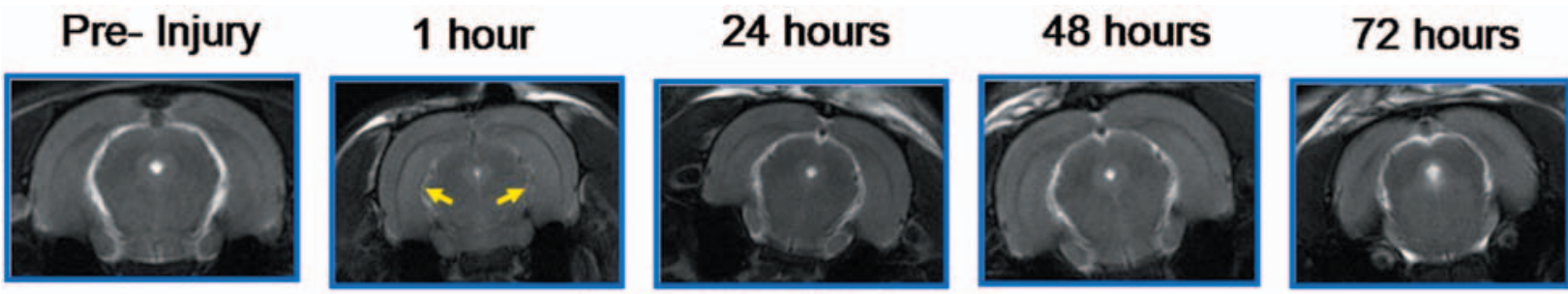

Scans at the midbrain level

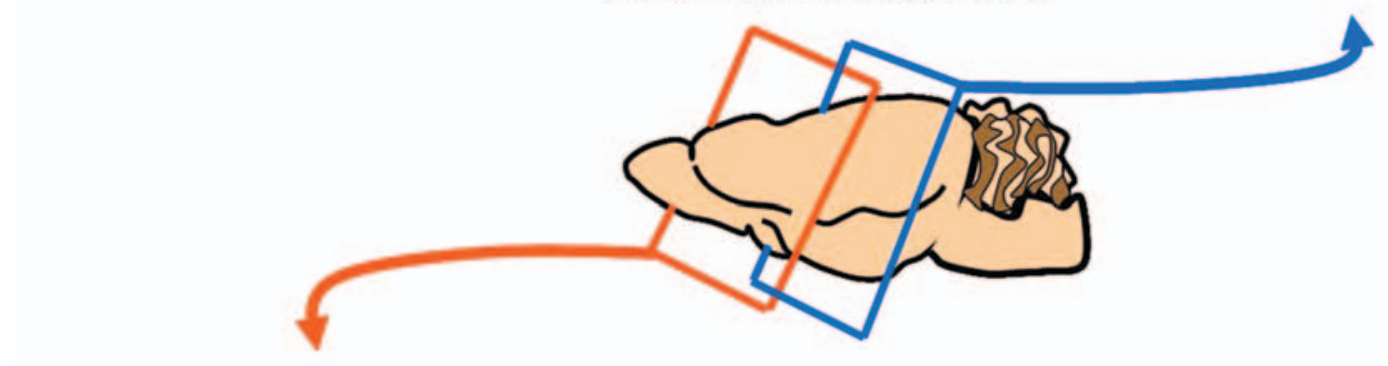

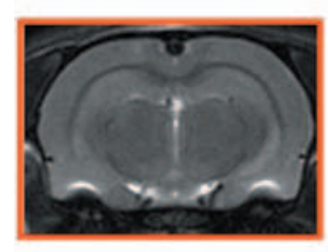

Pre- Injury

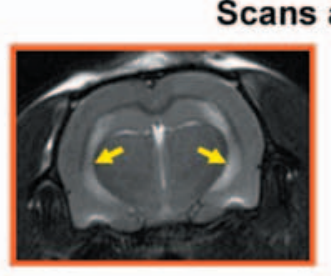

1 hour

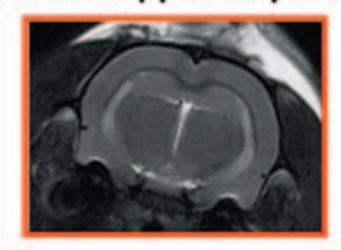

24 hours

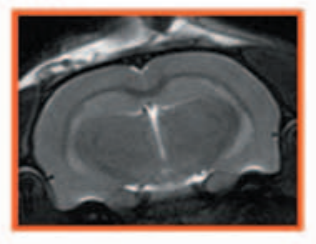

48 hours

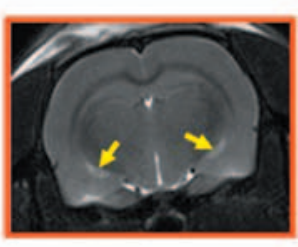

72 hours

FIG. 1. Sequential $\mathrm{T}_{2}$-weighted images (TR, $2.5 \mathrm{sec}$; TE, $60 \mathrm{msec}$ ) obtained after traumatic brain injury (TBI) from coronal sections of the forebrain, at the hippocampus-basal ganglia level (bottom panels), and midbrain (top panels). Forebrain coronal magnetic resonance imaging (MRI) scans correspond to the stereotaxic coordinates: interaural $4.48 \mathrm{~mm}$ and bregma $-4.52 \mathrm{~mm}$. Midbrain MRI scans to the coordinates interaural: $1.70 \mathrm{~mm}$ and bregma: $-7.30 \mathrm{~mm}$ (Paxinos et al., 1998). Note the disappearance of the cerebrospinal fluid signal surrounding the midbrain (top arrows, 1-h panel) and the appearance of hyperintensities in the hippocampal regions $1 \mathrm{~h}$ after TBI (bottom arrows, 1-h panel), which resume gradually (bottom arrows, $72 \mathrm{~h}$ panel).

\section{Univariate Statistical Analysis}

Statistical relationship between the changes in the concentration of cerebral metabolites with the time elapsed after injury was initially investigated. An ANOVA univariate test was run for each metabolite, revealing a statistically significant dependence of the metabolite concentration upon the time elapsed post-injury, except for 5'-adenosil-monophosphate (AMP; peak at $8.62 \mathrm{ppm}$ ) and acetate, which were not further investigated in this study. The hierarchy of the changes observed in the concentration of cerebral metabolites through the time postinjury was then investigated with the Snedecor's $F$ test. Table 3 shows the results obtained, with the cerebral metabolites arranged by the $R^{2}$ value. $\mathrm{Cr} / \mathrm{PCr}$, aspartate, Ino and Tau yielded $R^{2}$ values higher than 0.9 , being the molecules that hierarchically showed the strongest correlation between the changes in their concentration and the time elapsed after the injury. Among these four mol- ecules, aspartate did not present homogeneous variances, being excluded from further multivariate analysis.

In order to analyze the influence of the time elapsed post-injury on the change in concentration for each single metabolite, multiple Bonferroni tests were used for pairwise comparisons between each time point studied for every one of the metabolites investigated. Figure 4 shows, for illustrative purposes, the results obtained in the six metabolites showing both homogeneous variances and the highest $F$ values: $\mathrm{Cr} / \mathrm{PCr}$, Ino, Tau, NAA, threonine, and Glu. For each metabolite the pairwise comparisons between time groups are represented in squared matrix, with dark gray cells corresponding to statistical significant results. In addition, Dunnett tests were used to analyze the significance of the changes in concentration experienced by a given cerebral metabolite after injury, comparing between the value obtained at every time groups (9-72 h) and the single control group (sham operated). 
PASCUAL ET AL.

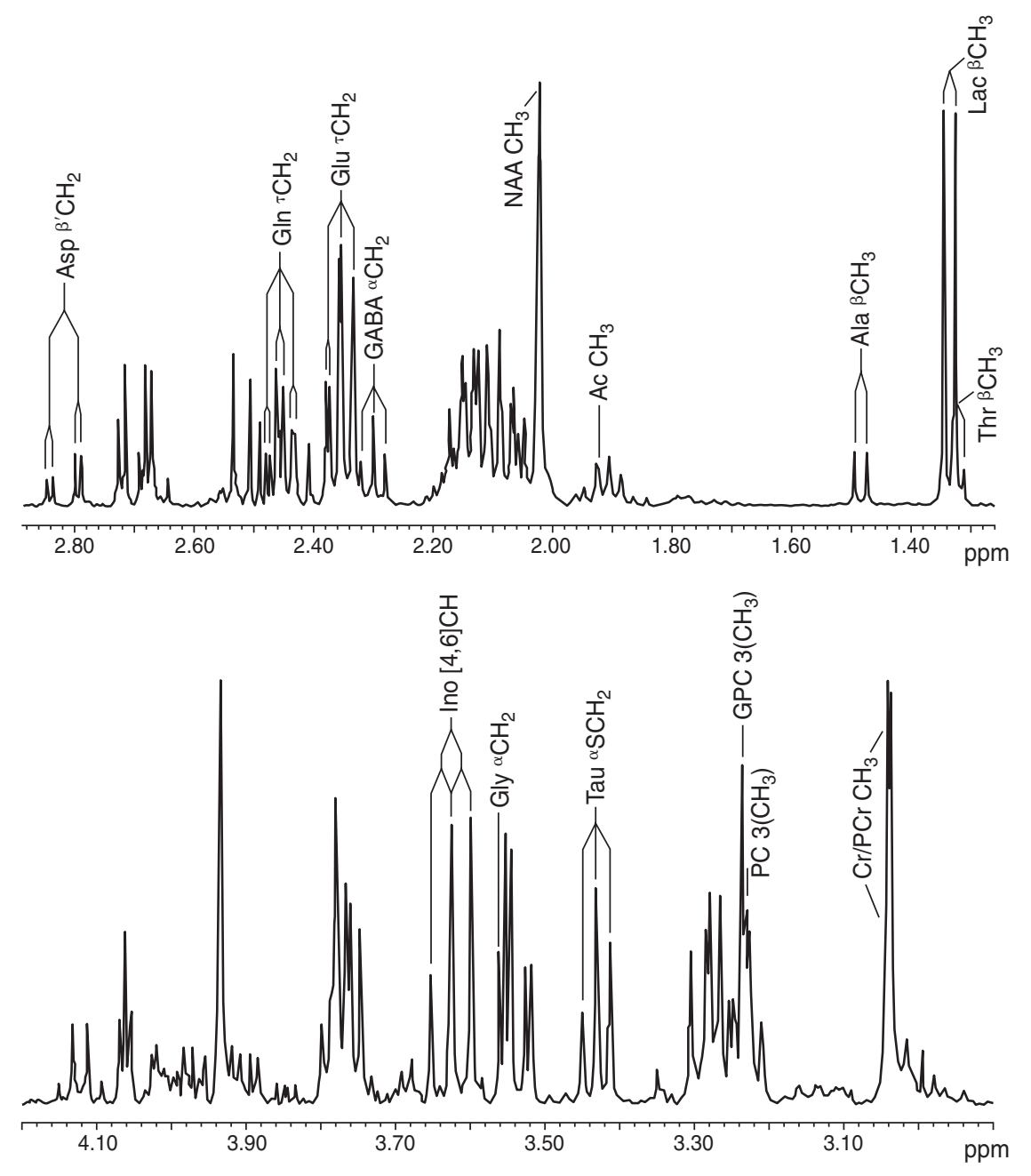

FIG. 2. High-resolution ${ }^{1} \mathrm{H}$ nuclear magnetic resonance spectrum $\left(360.13 \mathrm{MHz}, \mathrm{pH} 7.3,22^{\circ} \mathrm{C}\right)$ from a representative perchloric acid extract of rat brain, obtained $48 \mathrm{~h}$ after traumatic brain injury (TBI). Only the alyphatic regions are shown in the top (1.35-2.85 ppm) and bottom (2.90-4.20 ppm). The $\mathrm{CH}_{3}$, threonine (1.25 pm); $\mathrm{Lac} \mathrm{CH}_{3}$, lactate (1.35 ppm); Ala $\mathrm{CH}_{3}$, alanine (1.48 ppm); $\mathrm{Ac} \mathrm{CH}_{3}$, acetate (1.93 ppm); $\mathrm{NAA} \mathrm{CH}_{3}$. $\mathrm{N}$-acetylaspartic acid (2.05); $\mathrm{GABA} \mathrm{CH}_{2}, \gamma$-aminobutyryc acid (2.28 ppm); Glu $\mathrm{CH}_{2}$, glutamate (2.35 ppm); Gln $\mathrm{CH}_{2}$, glutamine (2.45 ppm); Asp $\mathrm{CH}_{2}$, aspartate (2.82 ppm); $\mathrm{Cr} / \mathrm{PCr} \mathrm{CH}_{3}$, creatine/phosphocreatine (3.05 ppm); Cho $\mathrm{CH}_{3}$, choline-containing compounds (3.20 ppm); Tau $\mathrm{CH}_{2}$, taurine (3.43 ppm); Gly $\mathrm{CH}_{2}$, glycine (3.56 ppm); Ino [4,6] CH, myo-inositol (3.62 ppm).

Significant differences between time groups obtained by Bonferroni tests must be interpreted considering the patterns of change in concentration exhibited by each metabolite. Only the three metabolites presenting the highest Snedecor's $F$ value of each pattern of evolution will be discussed here. Taurine depicted the first significant increment as compared to the control group $9 \mathrm{~h}$ after TBI and reached the maximal significant difference at $24 \mathrm{~h}$ post-injury. From this time on, Tau concentration started to decrease, this reduction becoming significant between 24 and $48 \mathrm{~h}$, and reaching the maximal significance at $72 \mathrm{~h}$. Glutamate showed the highest $F$ value of
Pattern 2, and the first significant difference for this molecule related to the control group was observed at $24 \mathrm{~h}$, being maintained with $48 \mathrm{~h}$. Then the concentration of Glu decreased abruptly rendering a value significantly different at $72 \mathrm{~h}$ than at 9, 24, and $48 \mathrm{~h}$ (gray cells). Finally, $\mathrm{Cr} / \mathrm{PCr}$ showed the highest $F$ value of Pattern 3. Significant differences for this metabolite were first observed at $9 \mathrm{~h}$. The difference increased then systematically and significantly until $48 \mathrm{~h}$, with significant differences observed between 9-24 and 24-48 $\mathrm{h}$, then decreasing sharply until $72 \mathrm{~h}$, a time point that showed significant differences to all other previous time points. 


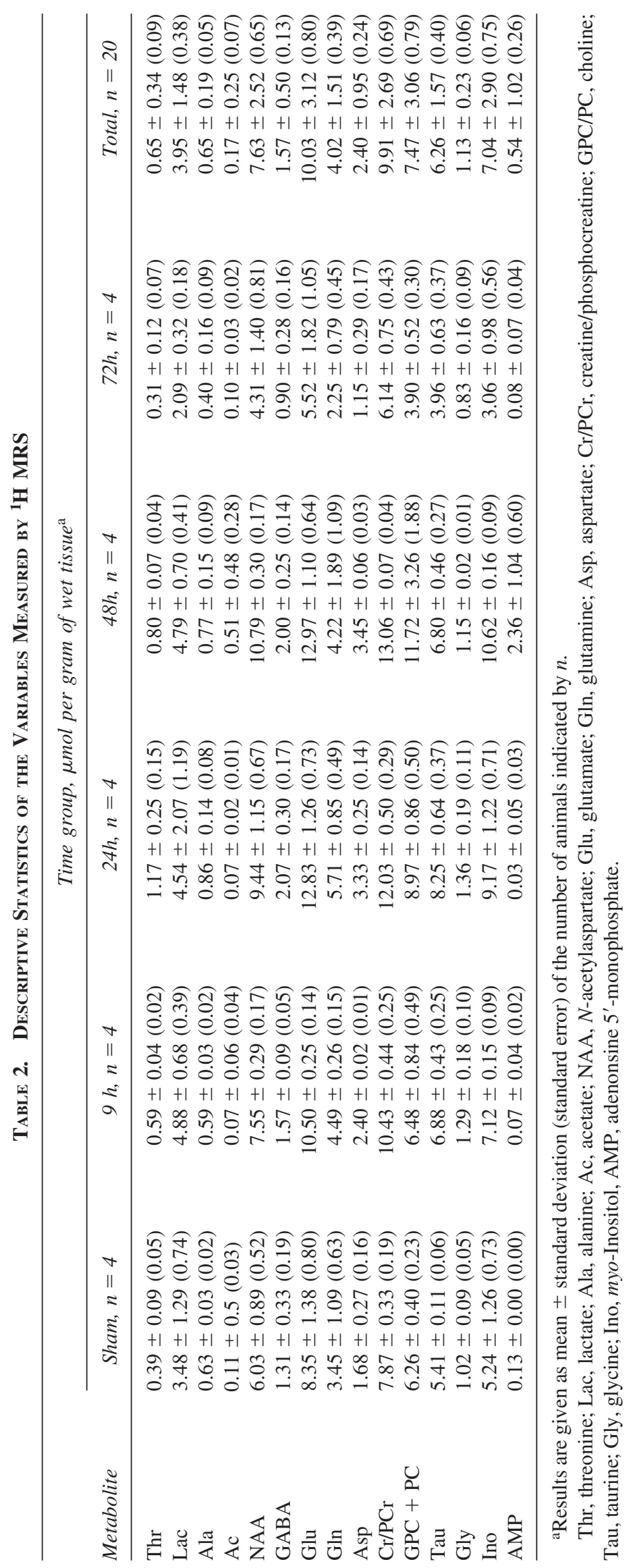


PASCUAL ET AL.
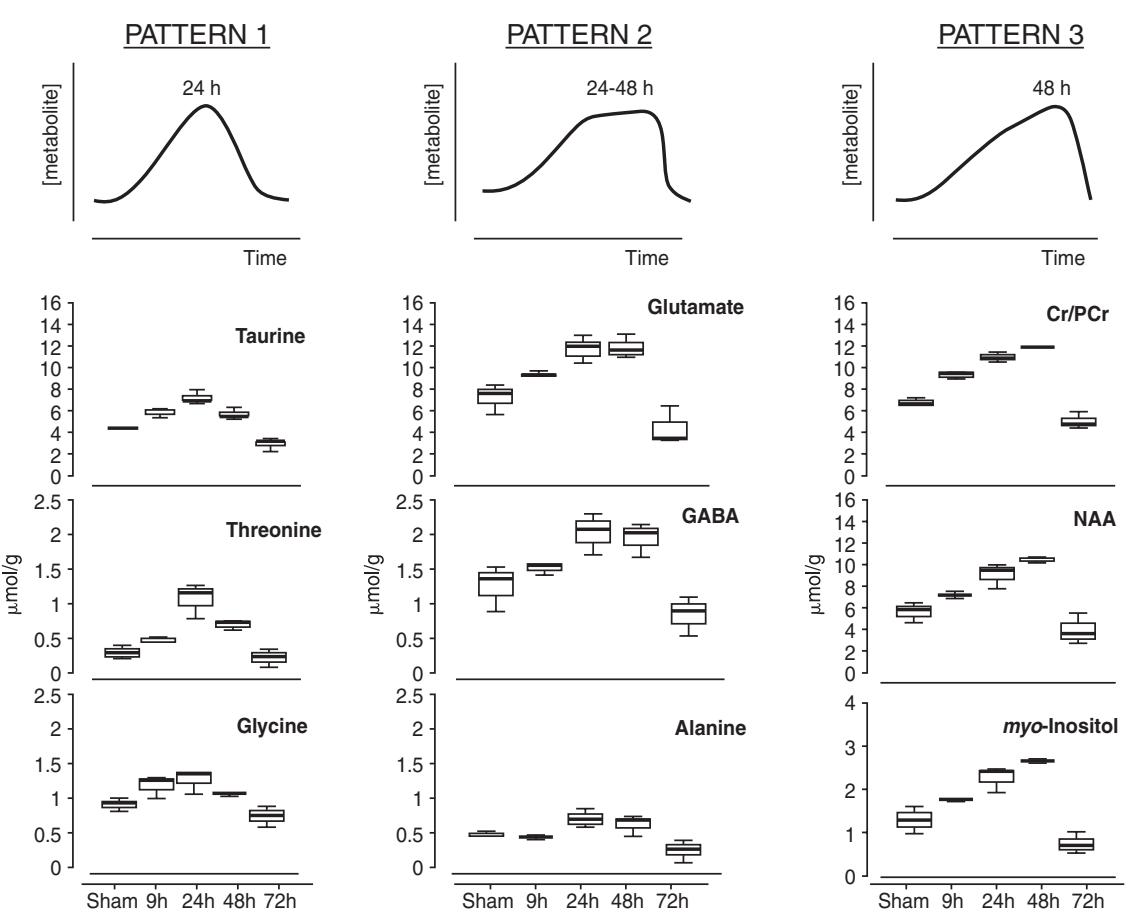

FIG. 3. Different patterns of change in the concentration of cerebral metabolites after traumatic brain injury (Pattern 1, left) Metabolites peaking $24 \mathrm{~h}$ after injury. (Pattern 2, center) Metabolites showing a plateau 24-48 h after the injury. (Pattern 3, right) Metabolites peaking $48 \mathrm{~h}$ after the injury. Abbreviations are the same as in Figure 2.

\section{Multivariate Statistical Analysis}

We obtained a model of variation in the concentration of cerebral metabolites regarding the time elapsed after injury, with potential predictive value, by using a stepwise discriminant analysis protocol as described in the

Table 3. Statistical ANOVA Univariate Analysis

\begin{tabular}{|c|c|c|c|}
\hline Metabolite & Snedecor's F test & $\begin{array}{c}\text { Significance } \\
\text { (p value) }\end{array}$ & Adjusted $R^{2}$ \\
\hline $\mathrm{Cr} / \mathrm{PCr}$ & $109.956^{\mathrm{a}}$ & 0.000 & 0.969 \\
\hline Asp & $68.371^{\mathrm{b}}$ & 0.000 & 0.951 \\
\hline Ino & 33.400 & 0.000 & 0.903 \\
\hline Tau & 32.809 & 0.000 & 0.901 \\
\hline NAA & 23.676 & 0.000 & 0.866 \\
\hline Thr & 19.179 & 0.000 & 0.839 \\
\hline Glu & 18.496 & 0.000 & 0.833 \\
\hline $\mathrm{GPC}+\mathrm{PC}$ & 10.633 & 0.001 & 0.733 \\
\hline GABA & 10.345 & 0.001 & 0.728 \\
\hline Ala & 6.730 & 0.007 & 0.621 \\
\hline Gly & 6.673 & 0.007 & 0.618 \\
\hline Gln & 3.997 & 0.340 & 0.461 \\
\hline
\end{tabular}

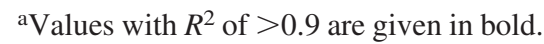

${ }^{\mathrm{b}}$ Variance not homogeneous as indicated.

For abbreviations of metabolites, see Table 2.
Methods. Among the metabolites that showed higher temporal discrimination in the univariate study, as reflected by the Snedecor $F$, we selected the three ones with maximum homogeneity of variance: $\mathrm{Cr} / \mathrm{PCr}$, myoinositol, and taurine. We allowed the program to select initially the best combination of these three metabolites to characterize each temporal situation. The combination of Tau and $\mathrm{Cr} / \mathrm{PCr}$ was selected then as the best one to discriminate between all time evolution points. However, it is possible to substitute $\mathrm{Cr} / \mathrm{PCr}$ by myo-inositol because of the osmotic role ascribed to the latter and the high correlation existent between the temporal course of both metabolites as proved in a Pearson test $(\rho=0.978)$.

Therefore, our results reveal that the time course of metabolic changes observed in this model of TBI, characterized by a predominant response of diffuse edema, can be adequately described through the combination of only two metabolites: taurine and myo-inositol. Table 4 shows the corresponding Fisher's functions obtained with the inclusion of Tau and Ino. Notably, these Fisher's functions were able to assign correctly the posttraumatic time course in all cases, providing a robust indication of the discriminating power of the model. In summary, this set of equations allowed us to predict the time elapsed after TBI, as a simple function of the cerebral concentrations of Ino and Tau detected by ${ }^{1} \mathrm{H}$ MRS. 


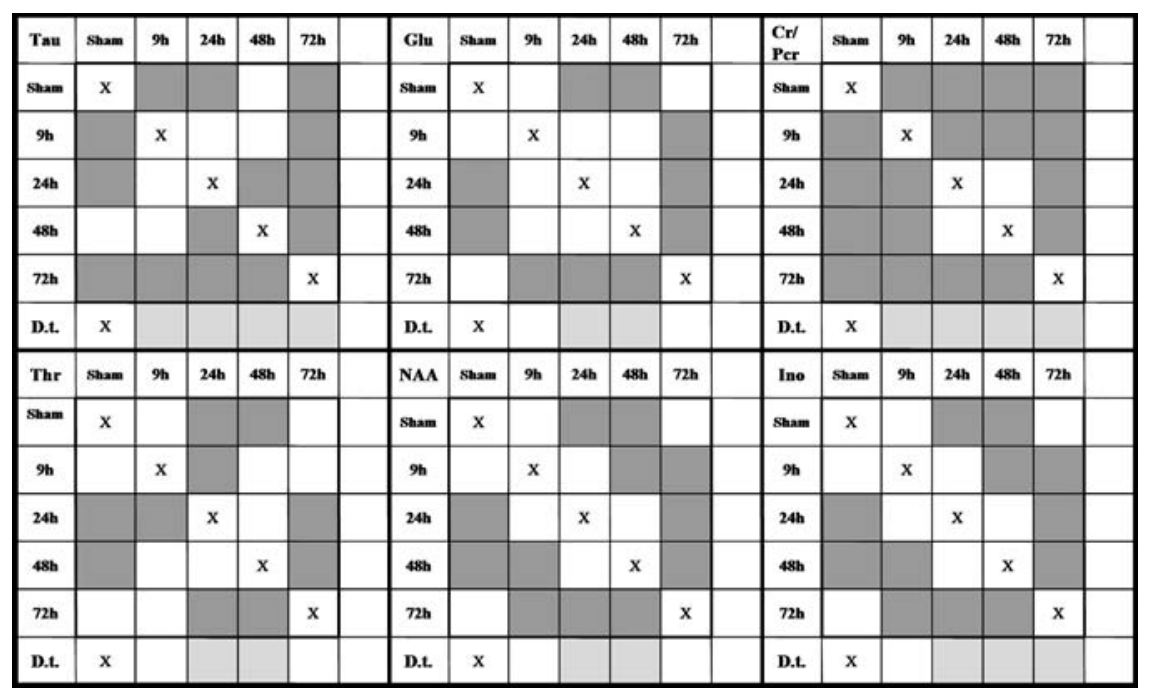

FIG. 4. Statistical analysis of the temporal changes in the concentration of some relevant cerebral metabolites as revealed by multiple comparisons Bonferroni and Dunnett tests. Only six metabolites were considered in the comparisons shown: taurine (Tau), glutamate (Glu), creatine/phosphocreatine (CR/Pcr), threonine (Thr), $N$-acetylaspartate (NAA), and Myo-inositol (Ino). For each metabolite, the pairwise comparisons between time groups are represented in a squared matrix, with dark gray cells corresponding to significant results. As an example, in the case of taurine, the pairwise comparisons that rendered a significant difference were sham-9 h, sham-24 h, sham-72 h, 9-72 h, 24-48 h, 24-72 h, and 48-72 h. Significant differences obtained by Dunnett test (D.t.) appear as light gray cells at the bottom row of each box. In the case of taurine, all time groups showed significant differences compared to the control group, as indicated by the light gray cells in the bottom row.

\section{DISCUSSION}

The present study has shown that the progression of post-traumatic brain damage induced by an experimental TBI model entails significant changes in the concentration of some cerebral metabolites, which follow specific time courses. Within the many molecules investigated, multivariate statistical analysis selected taurine and myo-inositol as the principal metabolites showing changes presumably correlated to the progression of the diffuse post-traumatic brain edema that characterizes Marmarou's TBI model. Unlike other experimental TBI models or the heterogeneous brain damage observed in most patients suffering a head injury, the weight drop

Table 4. Statistical Multivariate Analysis: Fisher's Functions Obtained by Linear Discriminant Analysis

\begin{tabular}{lc}
\hline Time group & Fisher's linear discriminant functions \\
\hline Sham & $3.905 \mathrm{Ino}+20.613 \mathrm{Tau}-67.607$ \\
$9 \mathrm{~h}$ & $5.545 \mathrm{Ino}+25.972 \mathrm{Tau}-110.672$ \\
$24 \mathrm{~h}$ & $7.466 \mathrm{Ino}+30.833 \mathrm{Tau}-163.107$ \\
$48 \mathrm{~h}$ & $10.086 \mathrm{Ino}+23.794 \mathrm{Tau}-136.046$ \\
$72 \mathrm{~h}$ & $1.854 \mathrm{Ino}+15.504 \mathrm{Tau}-35.153$ \\
\hline
\end{tabular}
fied.

$100 \%$ of the original grouped cases $(n=20)$ correctly classi- head impact model designed by Marmarou et al. induces a diffuse cerebral swelling, without showing neither a permanent blood-brain barrier breakdown nor scattered contusion foci (Foda et al., 1994; Marmarou et al., 1994). This post-traumatic diffuse brain swelling response has been extensively studied by electron microscopy and diffusion-weighted MR techniques either in experimental or clinical settings, both demonstrating a predominant intracellular type of edema as the major physiopathological alteration (Barzo et al., 1997; Castejon et al., 2000; Marmarou et al., 2000, 2006). However the early metabolic changes associated to the progression of the posttraumatic diffuse brain damage has not been analyzed in depth. The ex vivo analysis of whole brain extracts by high-resolution ${ }^{1} \mathrm{H}$ MRS offers a degree of sensitivity and reliability in spectra resolution that allows an exact quantification of the changes experienced in the cerebral metabolic profile after TBI. Unfortunately, the metabolic assessment obtained by this method represents only an average measure of the known heterogeneous susceptibility to traumatic injury shown by different brain structures. Preparation of extracts from frozen rat brains, with an average weight of less than $1.5 \mathrm{~g}$, does not allow the separation of tissue corresponding to defined cerebral structures for a regional analysis of metabolic posttraumatic changes. Nevertheless the diffuse cerebral damage induced by Marmarou's model is more suitable for ex- 
amining the progression of global brain metabolic changes than those models inducing a focal cerebral injury (Morales et al., 2005). Our results suggest that the shifts observed during the first $72 \mathrm{~h}$ post-injury in the concentration of taurine and myo-inositol, two molecules with a predominant osmotic role in the brain cells, could be used to estimate the time evolution of the diffuse brain edema response, as triggered by Marmarou's TBI model.

\section{TBI Studies by ${ }^{l} H$ MRS}

Changes in the concentration of cerebral metabolites after TBI have been previously reported in clinical studies in vivo by using ${ }^{1} \mathrm{H}$ MRS (Ross et al., 1998; Garnett et al., 2000; Son et al., 2000; Ashwal et al., 2004). The interpretation of the results of these clinical studies remains problematic, due to the high variability of the brain lesions occurring in each series and to the variable delay between the traumatic event and the acquisition of ${ }^{1} \mathrm{H}$ MR spectra. In addition, most of the clinical MR scanners equipped today with ${ }^{1} \mathrm{H}$ MRS packages operate at $1.5 \mathrm{~T}$, offering a spectrum resolution limited to only a few resonances, mainly NAA, $\mathrm{Cr} / \mathrm{PCr}$, and choline. A decrease in NAA and an increase in choline peaks were reported as the most significant alterations observed in closed head injured patients between several days to weeks after the injury (Ross et al., 1998; Garnett et al., 2000; Ashwal et al., 2004). Reduction in NAA concentration usually begins between days 5 and 10 after the injury; thus, this metabolic change is considered as a marker of the neuronal damage caused by diffuse axonal injury. Besides these findings, increments in $\mathrm{Cr} / \mathrm{PCr}$ and myo-inositol were also reported, and authors speculated that these increases could be due either to a hyperosmolar extracellular state developed by TBI (Ross et al., 1998) or to the process of astrogliosis triggered by the injury (Ashwal et al., 2004; Garnett et al., 2000). Concerning experimental TBI studies, a decrease of NAA has also been shown in contusive cortical areas by ${ }^{1} \mathrm{H}$ MRS performed either in vivo (Schuhmann et al., 2003) or on extracts of rat cerebral cortex (Rubin et al., 1997; Viant et al., 2005), in studies using controlled cortical impact injury models. In contrast with these previous studies, we have observed a continuous rise in the cerebral concentration of NAA during the first $48 \mathrm{~h}$ post-injury. This paradoxical finding is most probably related to the predominant development of diffuse brain edema in Marmarou's model as compared to the other experimental models mentioned above, which mainly cause brain contusions. Consequently, diffuse brain swelling and contusion cerebral foci represent two different posttraumatic lesions that may be characterized by distinctive metabolic profiles. In the case of a diffuse intracellular edema, NAA may act as an organic osmolyte that helps cells to com- pensate the osmolarity disturbance caused by a net intracellular water gain. As a support for this difference and in agreement with our results, a pilot study performed on rat brains subjected to fluid-percussion injury was able to detect by ${ }^{1} \mathrm{H}$ MRS an increase of NAA in edematous pericontusive regions during the first $24 \mathrm{~h}$ postinjury (Schuhmann et al., 2000). It is possible that the early phase of NAA increase associated with post-traumatic diffuse brain edema has been previously overlooked, due to the relatively long period of time needed to stabilize critical patients before any possible MR examination.

\section{TBI Effects on MRI}

Marmarou's TBI model reproduces a diffuse and long lasting intracellular type of edema that affects mainly glial cells but not neurons (Barzó et al., 1997; Castejon, 1998; Kimelberg, 1995; Marmarou, 1994, 2003; Mongin et al., 2005). The fundamental reasons for this difference remain unclear, but it has been proposed that glial posttraumatic swelling occurs as a buffering response, with the aim to normalize an altered extracellular millieu (Marmarou, 1994; Lang et al., 1998; Marmarou et al., 2000). The predominance of a net intracellular water increase as the main cause of the posttraumatic brain swelling has also been recently demonstrated on head injured patients by combining techniques of in vivo diffusion-weighted MRI and stable Xe-computarized tomography (Marmarou et al., 2000, 2006). Post-traumatic rat brain T2-weighted MRI studies, at $7 \mathrm{~T}$ obtained in six animals at 1, 9, 24, 48, and $72 \mathrm{~h}$ after the injury, have consistently shown some early signal changes, probably related to the development of diffuse cerebral edema, such as (i) the loss of cerebrospinal fluid at the peritroncular cistern $1 \mathrm{~h}$ after injury, a sign indicating expansion of brain volume that was also observed $1 \mathrm{~h}$ post-injury in a previous MRI study performed on this model (Barzó et al., 1997); and (ii) the symmetric hyperintensity signal areas appearing $1 \mathrm{~h}$ postinjury along both ventral hippocampi, which fade away during the following $72 \mathrm{~h}$ (Fig. 1 ). The presence of hyper-intensity signal changes seen early after TBI on $\mathrm{T}_{2}$-weighted MRI scans are considered to reflect edema formation (Albensi et al., 2000). A precise characterization of the predominant type of edema causing these $T_{2}$ MRI hyperintensities, extracellular-vasogenic versus intracellular-cytotoxic, cannot be ascertained unless apparent diffuse coefficient (ADC) maps are obtained (Albensi et al., 2000; Barzó et al., 1997). However, a recent MRI study on a diffuse TBI model has displayed similar hippocampal hyperintensities on posttraumatic ADC maps, between 4 and $24 \mathrm{~h}$ after the injury, which were considered the result of vasogenic edema formation (Cernak et al., 2004). An early and short-lasting blood-brain barrier breakdown for the first 
30 min post-injury has been proved in Marmarou's model (Barzó et al., 1997) causing a transitory vasogenic edema that could be most apparent at the hippocampi, which are neural structures with a known specific higher vulnerability to any type of injury.

\section{TBI Changes in Organic Osmolytes Detected by ${ }^{1} \mathrm{H} M R S$}

TBI induces significant disturbances in the extracellular biochemical composition. These are thought to be triggered by the massive increases in extracellular potassium $\left(\left[\mathrm{K}^{+}\right]_{\mathrm{o}}\right)$ and glutamate $\left([\mathrm{Glu}]_{\mathrm{o}}\right)$ levels, derived from the widespread neuronal membrane damage and depolarization (Katayama et al., 1995; Katoh et al., 1997; Bullock et al., 1998; Richards et al., 2003; Mongin et al., 2005). According to the homeostatic function of the extracellular space assigned to glial cells, the predominant glial swelling caused by TBI would be initiated by the massive influx of ions and water coupled with the uptake of the excess of $\left[\mathrm{K}^{+}\right]_{\mathrm{o}}$ and $[\mathrm{Glu}]_{\mathrm{o}}$ (Schneider et al., 1993; Katayama et al., 1995; Katoh et al., 1997). The term "neurotoxic edema" has been used for this specific type of intracellular glial edema, to distinguish it from the intracellular-cytotoxic type of swelling associated with cerebral ischemia (Marmarou et al., 2003). Our results have shown that ${ }^{1} \mathrm{H}$ MRS can be used to detect the early increments in Glu levels accompanying the initial posttraumatic brain damage. In this study, a progressive increase in Glu throughout the first $24 \mathrm{~h}$ after the injury was observed, which was maintained until $48 \mathrm{~h}$ post-impact. This is consistent with the increase in $[\mathrm{Glu}]_{\mathrm{o}}$ measured by microdialysis on head injured patients during the first 4 days after the traumatic event (Bullock et al., 1998; Richards et al., 2003). The progressive increase in tissue Glu early after TBI has not been previously reported in other models of TBI. Interestingly, recent clinical investigations analyzing early post-traumatic cerebral metabolic changes by in vivo ${ }^{1} \mathrm{H} \mathrm{MRS}$, have reported an increase in Glx (Glu/Gln) in normal appearing brain tissue (Shutter et al., 2004; Ashwal et al., 2004). These findings were interpreted as an effect of early excitotoxic injury following the TBI and were correlated with a worse outcome (Shutter et al., 2004), lending support to the results reported in our experimental study.

${ }^{1} \mathrm{H}$ MRS is also proved in this study to provide a useful tool for the early detection of increments induced by TBI on other molecules, such as taurine and myo-inositol, whose levels seem to correlate to the progression of a post-traumatic diffuse brain swelling response. The rise in taurine and myo-inositol levels detected by ${ }^{1} \mathrm{H}$ MRS, during the first 24 and $48 \mathrm{~h}$ postinjury, respectively, may reflect an adaptive metabolic response to the volume increase experienced by brain cells during the progression of post-traumatic edema. In the case of Tau, our results show a progressive rise until $24 \mathrm{~h}$ post-injury, followed by an abrupt drop. A similar pattern of increment for Tau was measured in the cerebrospinal fluid (CSF) of rat brains undergoing a fluid percussion brain injury, and this change was correlated to the development of glutamateinduced post-traumatic brain swelling (Stover et al., 2000). Rises in the CSF levels of Tau and Glu has also been observed in head-injured patients suffering diffuse brain swelling, from days 1 to 14 after the injury, but with a maximum peak between days 1 and 5 post-injury (Stover et al., 1999; Seki et al., 2005). These increments were explained by the authors as the combined effects of a direct neuronal membrane damage, post-traumatic astrocytic swelling and failing of buffering glial mechanisms, and not by a blood-brain barrier breakdown, as other amino acids did not show similar increments.

\section{Role of Organic Osmolytes in TBI}

Taurine and myo-inositol represent two of the most important organic osmolytes in the adult mammalian brain (Dutton et al., 1991; McManus et al., 1995). Cerebral osmolytes have the property to retain or release intracellular water without perturbing significantly the resting cell membrane potential, contributing in this way to preserve the brain cell functions (McManus et al., 1995; Pasantes-Morales et al., 1997; Lang et al., 1998). Organic osmolytes are thought to be accumulated or released by brain cells as a compensatory mechanism for cell volume homeostasis in situations of chronic changes of extracellular osmolality (Strange et al., 1992; Pasantes-Morales et al., 1994; McManus et al., 1995; Rumpel et al., 2003). Notably, increases in the brain content of the organic osmolytes Ino and Tau have been observed in clinical situations of chronic high extracellular osmolality, such as long term hypernatremia (Obrist et al., 1984; Lee et al. 1994). On the contrary, when an acute swelling of brain tissue is triggered by an hypoosmotic shock, a decrease in the levels of a wide range of osmotically active molecules has invariably been seen with ${ }^{1} \mathrm{H}$ MRS, including NAA, creatine, Glu, GABA, and Tau (Bothwell et al., 2001).

However, it should be noted that, even under isosmotic extracellular conditions, as those present in cerebral ischemia or in TBI, cell volume homeostasis can also be challenged (Lang et al., 1998; Pasantes-Morales et al., 2000). The sustained cerebral edema observed in vivo after an ischemic or a traumatic event contrasts with the rapid regulatory volume decrease (RVD) response observed in vitro in cultured astrocytes exposed to a hypoosmolar medium (Lang et al., 1998; McManus et al., 1995). This RVD response consists of a rapid partial volume cell correction observed in many isolated cells in 
vitro after suffering a sudden swelling (Baumgarten et al., 2001; Pasantes-Morales et al., 1997, 2000). The less efficient RVD response observed in vivo in swollen astrocytes after a TBI can be explained following the concept of functional and metabolic neuronal-glial coupling (Magistretti et al., 1999). TBI would elicit a long-lasting glial swelling as a result of the predominant glial correction of ionic and amino acid extracellular disturbances caused by the impact, being this homeostatic function preferential over the glial cell volume correction, in order to avoid neuronal dysfunction (Kempski et al., 1994). As support of this hypothesis, it has been demonstrated that glial cells protect neurons against neurotoxicity under ischemic simulated conditions, by taking up the excess of extracellular glutamate released by neurons, a behavior conducted at expense of maintaining a chronic swollen state (Rosenberg et al., 1989). This favored glial glutamate buffering response has also been confirmed in vivo in an experimental model of focal cerebral ischemia by ${ }^{13} \mathrm{C}$ MRS techniques (Pascual et al., 1998).

The rise in the cerebral levels of taurine and myo-inositol detected by ${ }^{1} \mathrm{H}$ MRS in our study suggests that a sustained increase of these osmolytes may be associated in vivo with the presence of posttraumatic intracellular edema due to the absence of an early and efficient RVD response (McManus et al., 1995). Likewise, increments in cerebral content of myo-inositol have been detected by ${ }^{1} \mathrm{H}$ MRS during the maintenance of ischemic brain swelling (Nonaka et al., 1998; Rumpel et al., 2003). Notably, a transfer of taurine from neurons to astrocytes, with the accumulation of this organic osmolyte in the latter cells, has been demonstrated in vivo in pathological situations that cause a glial swelling, such as experimental brain ischemia and chronic hypoosmolar extracellular conditions (Nagelhus et al., 1993; Torp et al., 1991). By this organic osmolytes buildup, the glial edema would be maintained, whereas neurons would be spared and protected from the deleterious effects of swelling.

\section{${ }^{1}$ H MRS Detection of Organic Osmolytes In Vivo}

The results of this study remain encouraging, as highresolution ${ }^{1} \mathrm{H}$ MRS has proved itself as a powerful tool for the temporal discrimination of complex metabolic conditions characterized by continuous changes of the metabolic profile, such as TBI. The degree of sensitivity and reliability in ${ }^{1} \mathrm{H}$ NMR spectra resolution performed on whole brain extracts allows an exact quantification of the resonances corresponding to most organic osmolytes, including Tau and Ino. This degree of resolution can hardly be reached in vivo with present MR equipment, thus precluding a direct clinical application of our data to discriminating the temporal evolution of posttraumatic brain swelling. The current limited spectra resolution of in vivo ${ }^{1} \mathrm{H}$ MRS is not only due to the low magnetic field strength available, but also to the macro- and micro-susceptibility effects caused in vivo by paramagnetic species, such as the air-tissue and bone-tissue interfaces or the blood flow in microvessels (Gruetter et al., 1998). However, the recent development of new techniques for an automatic adjustment of second-order shimming coils (FASTMAP), together with the use of ultra-short echotimes and efficient sequence methods of water signal suppression (VAPOR), have dramatically improved the resolution of ${ }^{1} \mathrm{H}$ MR spectra in vivo (Thác et al., 1999, 2001). The sensitivity of ${ }^{1} \mathrm{H}$ MR spectra obtained in vivo both from the rat (at 9.4 $\mathrm{T}$ ) and the human brain (at $7 \mathrm{~T}$ ) by using these methods allows an unambiguous and exact discrimination of all the metabolites shown by ${ }^{1} \mathrm{H} \mathrm{MR}$ spectra from whole brain extracts, including Glu, Gln, Tau, and Ino (Thác, 1999, 2001). Therefore, the possibility is real of using ${ }^{1} \mathrm{H}$ MRS in the near future in clinical settings to track in vivo changes in cerebral neurotransmitters and organic osmolytes after a head injury.

\section{CONCLUSION}

In conclusion, this study has shown that changes in the content of two cerebral organic osmolytes, taurine and myo-inositol, can be analyzed on extracts of whole rat brain by ${ }^{1} \mathrm{H}$ MRS and used to describe the time evolution of the post-traumatic diffuse brain injury. Our findings highlight the importance of the changes induced by TBI in the content of specific brain molecules, such as Tau and Ino, which play an important role as organic osmolytes. These metabolic changes can be used to describe the dynamic deleterious effects of the TBI, in addition to the changes induced in other metabolites such as NAA, $\mathrm{Cr} / \mathrm{PCr}$, or $\mathrm{Glu}$, considered in previous studies. As these metabolic effects were quantified on an experimental TBI model that induces a predominant response of diffuse brain edema, our results suggest that early increments in the content of organic osmolytes are involved in the development of post-traumatic brain swelling in vivo. The clinical impact of tracking the changes in cerebral organic osmolytes in vivo cannot be ascertained until future studies will be able to measure the early changes of these molecules in head-injured patients by improved highfield ${ }^{1} \mathrm{H}$ MRS methods.

\section{ACKNOWLEDGMENTS}

We are indebted to Teresa Navarro for expert operation of the small animal and MRI instrumentation. We are also grateful to Kristine Osmond and David King for 
their linguistic assistance. This work was partly supported by Spanish Ministry of Education and Science (grants SAF 2001-224 and SAF 2004-03197 to J.M.R. and S.C.) and by Spanish Ministry of Health (grants FISss C03/08, C03/10, and G03/155 to J.M.R. and S.C.).

\section{REFERENCES}

AFIFI, A., CLARK, V.A., and MAY, S. (2004). ComputerAided Multivariate Analysis, 4th ed. Chapman \& Hall/CRC: Boca Raton, FL.

ALBENSI, B.C., KNOBLACH, S.M., CHEW, B.G.M., O'REILLY, M.P., FADEN, A.I., and PEKAR, J.J. (2000). Diffusion and high-resolution MRI of traumatic brain injury in rats: time course and correlation with histology. Exp. Neurol. 162, 61-72.

ALEXANDER, J.J., ZWINGMANN, C., and QUIGG, R. (2005). MRL/lpr have alterations in brain metabolism as shown with $\left[{ }^{1} \mathrm{H}-{ }^{13} \mathrm{C}\right] \mathrm{NMR}$ spectroscopy. Neurochem. Int. 47, 143-151.

ASHWAL, S., HOLSHOUSER, B., TONG, K., et al. (2004). Proton spectroscopy detected myoinositol in children with traumatic brain injury. Pediatr. Res. 56, 630-638.

BARZO, P., MARMAROU, A., FATOUROS, P., CORWIN, F., and DUNBAR, J.G. (1997). Acute blood-brain barrier changes in experimental closed head injury as measured by MRI and Gd-DTPA. Acta Neurochir. (Suppl.) 70, 243-246.

BARZO, P., MARMAROU, A., FATOUROS, P., HAYASAKI, K., and CORWIN, F. (1997). Contribution of vasogenic and cellular edema to traumatic brain swelling measured by diffusion-weighted imaging. J. Neurosurg. 87, 900-907.

BAUMGARTEN, C.M. and FEHER, J.J. (2001). Osmosis and the regulation of cell volume, in: Cell Physiology. Source Book, 2nd ed. N. Sperelakis (ed), Academic Press: San Diego, pps. 253-293.

BEHAR, K.L. and OGINO, T. (1991). Assignment of resonance in the ${ }^{1} \mathrm{H}$ spectrum of rat brain by two-dimensional shift correlated and J-resolved NMR spectroscopy. Magn. Reson. Med. 17, 285-303.

BOTHWELL, J.H., RAE, C., DIXON, R.M., STYLES, P., and BHAKOO, K.K. (2001). Hypo-osmotic swelling-activated release of organic osmolytes in brain slices: implications for brain oedema in vivo. J. Neurochem. 77, 1632-1640.

BOUMA, G.J., MUIZELAAR, J.P., and FATOUROS, P. (1998). Pathogenesis of traumatic brain swelling: role of cerebral blood volume. Acta Neurochir. (Suppl.) 71, 272-275.

BULLOCK, R., ZAUNER, A., WOODWARD, J.J., et al. (1998). Factors affecting excitatory amino acid release following severe human head injury. J. Neurosurg. 89, 507-518.
CASTEJON, O.J. (1998). Morphological astrocytic changes in complicated human brain trauma. A light and electron microscopic study. Brain Inj. 12, 409-427.

CERDAN, S., PARRILLA, R., SANTORO, J., and RICO, M. (1985). ${ }^{1} \mathrm{H}$ NMR detection of cerebral myo-inositol. FEBS Lett. 187, 167-172.

CERDAN, S., and SEELIG, J. (1990). NMR studies of metabolism. Annu. Rev. Biophys. Biophys. Chem. 19, 43-67.

CERNAK, I., VINK, R., ZAPPLE, D.N., et al. (2004). The pathobiology of moderate diffuse traumatic brain injury as identified using a new experimental model of injury in rats. Neurobiol. Dis. 17, 29-43.

DUTTON, G.R., BARRY, M., SIMMONS, M.L., and PHILIBERT, R.A. (1991). Astrocyte taurine. Ann. N.Y. Acad. Sci. 633, 489-500.

FODA, M., and MARMAROU, A. (1994). A new model of diffuse brain injury in rats. Part II: Morphological characterization. J. Neurosurg. 80, 301-313.

GARNETT, M.R., BLAMIRE, A.M., CORKILL, R.G., CADOUX-HUDSON, T.A., RAJAGOPALAN, B., and STYLES, P. (2000). Early proton magnetic resonance spectroscopy in normal-appearing brain correlates with outcome in patients following traumatic brain injury. Brain 123, 2046-2054.

GRUETTER, R., WEISDORF, S.A., RAJANAYAGAN, V., et al. (1998). Resolution improvements in in vivo ${ }^{1} \mathrm{H}$ NMR spectra with increased magnetic field strength. J. Magn. Reson. 135, 260-264.

ITO, J., MARMAROU, A., FATOUROS, P., and CORWIN, F. (1996). Characterization of edema by diffusion-weighted imaging in experimental traumatic brain injury. J. Neurosurg. 84, 97-103.

KATAYAMA, Y., MAEDA, T., KOSHINAGA, M., KAWAMATA, T., and TSUBOKAWA, T. (1995). Role of excitatory amino acid-mediated ionic fluxes in traumatic brain injury. Brain Pathol. 5, 427-435.

KATOH, H., SIMA, K., NAWASHIRO, H., WADA K., and CHIGASAKI, H. (1997). The effect of MK-801 on extracellular neuroactive amino acids in hippocampus after closed injury followed by hypoxia in rats. Brain Res. 758, 153-162.

KELLY, D.F., KORDESTANI, R.K., MARTIN, N.A., et al. (1996). Hyperemia following traumatic brain injury: relationship to intracranial hypertension and outcome. J. Neurosurg. 85, 762-771.

KEMPSKI, O., and VOLK, C. (1994). Neuron-glial interaction during injury and edema of the CNS. Acta Neurochir. (Suppl.) 60, 7-11.

KIMELBERG, H.K. (1995). Current concepts in brain edema: review of laboratory investigations. J. Neurosurg. 83, 1051-1059.

KLATZO, I. (1967). Presidential Address: neuropathological aspects of brain edema. J. Neuropathol. Exp. Neurol. 26, $1-13$. 
LANG, F., BUSCH, G.L., RITTER, M., et al. (1998). Functional significance of cell volume regulatory mechanisms. Physiol. Rev. 78, 247-306.

LEE, J.H., ARCINUE, E., and ROSS, B.D. (1994). Organic osmolytes in the brain of an infant with hypernatremia. N Engl. J. Med. 331, 439-442.

LIN, A., ROSS, B.D., HARRIS, K., and WONG, W. (2005). Efficacy of proton magnetic resonance spectroscopy in neurological diagnosis and neurotherapeutic decision making. NeuroRx 2, 197-214.

LOBATO, R.D. (1993). Post-traumatic brain swelling. Adv. Tech. Stand. Neurosurg. 20, 3-38.

LUST, W., RICCI, A., SELMAN, W., and RATCHESOR, R. (1989). Methods of fixation of nervous tissue for use in the study of cerebral energy metabolism, in: Neuromethods 11: Carbohydrates and Energy Metabolism. A. Boulton, G. Baker, and R. Butterworth (eds), Humana Press: Clifton, NJ, pps. 1-41.

MAGISTRETTI, P.J., PELLERIN, L., ROTHMAN, D.L., and SHULMAN, R.G. (1999). Energy on demand. Science 283, 496-497.

MARMAROU, A. (1994). Traumatic brain edema: an overview. Acta Neurochir. (Suppl.) 60, 421-424.

MARMAROU, A. (2003). Pathophysiology of traumatic brain edema: current concepts. Acta Neurochir. (Suppl.) 86, 7-10.

MARMAROU, A., FODA, M., VAN DEN BRINK, W., CAMPBELL, J., KITA, H., and DEMETRIADOU, K. (1994). A new model of diffuse brain injury in rats. Part I: Pathophysiology and biomechanics. J. Neurosurg. 80, 291-300.

MARMAROU, A., FATOUROS, P.P., BARZÓ P., et al. (2000). Contribution of edema and cerebral blood volume to traumatic brain swelling in head-injured patients. J. Neurosurg. 93, 183-193.

MARMAROU, A., SIGNORETTI, S., FATOUROS, P.P., PORTELLA, G., AYGOK, G.A., and BULLOCK, M.R. (2006). Predominance of cellular edema in traumatic brain swelling in patients with severe head injuries. J. Neurosurg. 104, 720-730.

MARSHALL, L.F., MARSHALL, S.B., KLAUBER, M.R., et al. (1991). A new classification of head injury based on computed tomography. J. Neurosurg. 75, S14-S20.

MCMANUS, M.L., CHURCHWELL, K.B., and STRANGE, K. (1995). Regulation of cell volume in health and disease. N. Engl. J. Med. 333, 1260-1266.

MONGIN, A.A., and KIMELBERG, H.K. (2005). Astrocyte swelling in neuropathology, in: Neuroglia, 2nd ed. H. Kettenmann and B.R. Ransom (eds), Oxford University Press: New York, pps. 550-562.

MORALES, D.M., MARKLUND, N., LEBOLD, D., et al. (2005). Experimental models of traumatic brain injury: do we really need to build a better mousetrap? Neuroscience 136, 971-989.

NAGELHUS, E.A., LEHMAN, A., and OTTERSEN, O.P. (1993). Neuronal-glial exchange of taurine during hypo-osmotic stress: a combined immunocytochemical and biochemical analysis in rat cerebellar cortex. Neuroscience 54, 615-631.

NONAKA, M., YOSHIMINI, T., KOHMURA, E., WAKAYAMA, A., YAMASHITA, T., and HAYAKAWA, T. (1998). Changes in brain osmolytes in experimental cerebral ischemia. J. Neurol. Sci. 157, 25-30.

OBRIST, W.D., LANGFITT, T.W., JAGGI, J.L., CRUZ, J., and GENNARELLI, T.A. (1984). Cerebral blood flow and metabolism in comatose patients with acute head injury. J. Neurosurg. 61, 241-253.

PASANTES-MORALES, H., MURRAY, R.A., SÁNCHEZOLEA R., and MORAN, J. (1994). Regulatory volumen decrease in cultured astrocytes. II: Permeability pathway to amino acids and polyols. Am. J. Physiol. 26, C172-C178.

PASANTES-MORALES, H., and SCHOUSBOE, A. (1997). Role of taurine in osmoregulation in brain cells: mechanisms and functional implications. Amino Acids 12, 281-292.

PASANTES-MORALES, H., FRANCO, R., TORRES-MARQUEZ, M.E., HERNÁNDEZ-FONSECA, K., and ORTEGA, A. (2000). Amino acid osmolytes in regulatory volume decrease and isovolumetric regulation in brain cells: contribution and mechanisms. Cell Physiol. Biochem. 10, 361-370.

PASCUAL, J.M., CARCELLER, F., RODA, J.M., and CERDÁN, S. (1998). Glutamate, glutamine and GABA as substrates for the neuronal and glial compartments after focal cerebral ischemia in rats. Stroke 29, 1048-1057.

PAXINOS, G., and WATSON, C. (1998). The Rat Brain in Stereotaxic Coordinates, 4th ed. Academic Press: San Diego. RICHARDS, D.A., TOLIAS, C.M., SGOUROS, S., and BOWERY G. (2003). Extracellular glutamine to glutamate ratio may predict outcome in the injured brain: a clinical mycrodialysis study in children. Pharmacol. Res. 48, 101-109.

ROSENBERG, P.A., and AIZENMAN, E. (1989). Hundredfold increase in neuronal vulnerability to glutamate toxcitity in astrocyte-poor cultures or rat cerebral cortex. Neurosci. Lett. 103, 162-168.

ROSS, B.D., ERNST, T., KREIS, R., et al. (1998). ${ }^{1} \mathrm{H}$ MRS in acute traumatic brain injury. J. Magn. Reson. Imaging 8, 829-840.

RUBIN, Y., CECIL, K., WEHRLI, S., McINTOSH, T.K., LENKINSKI, R.E., and SMITH, D.H. (1997). High-resolution ${ }^{1} \mathrm{H}$ NMR spectroscopy following experimental brain trauma. J. Neurotrauma 14, 441-449.

RUMPEL, H., LIM, W.E., CHANG, H.M., et al. (2003). Is myo-inositol a measure of glial swelling after stroke? A magnetic resonance study. J. Magn. Reson. Imaging 17, 11-19. 
SCHNEIDER, G.-H., BAETHMANN, A., and KEMPSKI, O. (1993). Mechanisms of glial cell swelling induced by glutamate. Can. J. Physiol. Pharmacol. 70, S334-S343.

SCHUHMANN, M.U., STILLER, D., THOMAS, S., BRINKER, T., and SAMII, M. (2000). ${ }^{1} \mathrm{H}$ MR spectroscopic monitoring of postraumatic metabolism following controlled cortical impact injury: pilot study. Acta Neurochir. (Suppl.) 76, 3-7.

SCHUHMANN, M.U., STILLER, D., SKARDELLY, M., et al. (2003). Metabolic changes in the vicinity of brain contusions: a proton magnetic resonance spectroscopy and histology study. J. Neurotrauma 20, 725-743.

SEKI, Y., KIMURA, M., MIZUTANI, N., FUJITA, M., AIMI, Y., and SUZUKI, Y. (2005). Cerebrospinal fluid taurine after traumatic brain injury. Neurochem. Res. 30, 123-128.

SHUTTER, L., TONG, K.A., and HOLSHOUSER, B.A. (2004). Proton MRS in acute traumatic brain injury: role for glutamate/glutamine and choline for outcome prediction. J. Neurotrauma 21, 1693-1705.

SON, B.C., PARK, C.K., CHOI, B.G., et al. (2000). Metabolic changes in pericontusional oedematous areas in mild head injury evaluated by ${ }^{1} \mathrm{H}$ MRS. Acta Neurochir. (Suppl.) 76, 6-13.

STOVER, J.F., MORGANTI-KOSMANN, M.C., STOCKER, R., KEMPSKI, O.S., and KOSSMANN, T. (1999). Glutamate and taurine are increased in ventricular cerebrospinal fluid of severely brain-injured patients. J. Neurotrauma 16, 135-142.

STOVER, J.F., and UNTERBERG, A.W. (2000). Increased cerebrospinal fluid glutamate and taurine concentrations are associated with traumatic brain edema formation in rats. Brain Res. 875, 51-55.

STRANGE, K., and MORRISON, R. (1992). Volume regulation during recovery from chronic hypertonicity in brain glial cells. Am. J. Physiol. 263, C412-C419.
TKAC, I., STARCUK, Z., CHOI, I.-Y., and GRUETTER, R. (1999). In vivo ${ }^{1} \mathrm{H}$ NMR spectroscopy of rat brain at $1 \mathrm{~ms}$ echo time. Magn. Reson. Med. 41, 649-656.

TKAC, I., ANDERSEN, P., ADRIANY, G., MERKLE, H., UGURBIL, K., and GRUETTER, R. (2001). In vivo ${ }^{1} \mathrm{H}$ NMR Spectroscopy of the human brain at 7T. Magn. Reson. Med. 46, 451-456.

TORP, R., ANDINE, P., HAGBERG, H., KARAGULLE, T., BLACKSTAD, T.W., and OTTERSEN, O.P. (1991). Cellular and subcellular redistribution of glutamate-, glutamine-, and taurine-like immunoreactivities during forebrain ischemia: a semiquantitative electron microscopic study in rat hippocampus. Neuroscience 41, 433-447.

UNTERBERG, A.W., STOVER, J.F., KRESS, B., and KIENING, K.L. (2004). Edema and brain trauma. Neuroscience 129, 1021-1029.

VIANT, M.R., LYETH, B.G., MILLER, M.G., and BERMAN, R.F. (2005). An NMR metabolomic investigation of early metabolic disturbances following traumatic brain injury in a mammalian model. NMR Biomed. 18, 507-516.

WEBER, D.C., and SKILLINGS, J.H. (2000). A First Course in the Design of Experiments. A Linear Models Approach. CRC Press LLC: Boca Raton, FL.

Address reprint requests to: José M. Pascual, M.D., Ph.D. Department of Neurosurgery Hospital Universitario de La Princesa c/Diego de León 62 Madrid 28006, Spain

E-mail: jmpascual@iib.uam.es 